\title{
Respiratory symptoms and mortality in four general population cohorts over 45 years
}

Amund Gulsvik ${ }^{1}$, Per S. Bakke ${ }^{1}$, Jan Brøgger ${ }^{2}$, Rune Nielsen $^{1,3}$, Knut Stavem ${ }^{4,5,6}$

${ }^{1}$ Dept. of Clinical Science, Faculty of Medicine, University of Bergen, Bergen, Norway.

${ }^{2}$ Section for Clinical Neurophysiology, Department of Neurology, Haukeland University Hospital, Bergen, Norway

${ }^{3}$ Dept. of Thoracic Medicine, Haukeland University Hospital, Bergen, Norway.

${ }^{4}$ Institute of Clinical Medicine, University of Oslo, Lørenskog, Norway

${ }^{5}$ Department of Pulmonary Medicine, Medical Division, Akershus University Hospital, Lørenskog, Norway

${ }^{6}$ Health Services Research Unit, Akershus University Hospital, Lørenskog, Norway

Correspondence to: Knut Stavem, Department of Pulmonary Medicine, Medical Division Akershus University Hospital, N-1478 Lørenskog, Norway

mobile tel. +4797542157

work tel. +4767968710

email: knut.stavem@medisin.uio.no 


\section{Abstract \\ Objective}

This study assessed the association between respiratory symptoms and mortality in four cohorts of the general population in Norway aged $15-75$ years and in selected subgroups in the pooled sample.

Methods

The study comprised 158,702 persons, who were drawn randomly from the Norwegian population register. All subjects received a standardized, self-administered questionnaire on 11 respiratory symptoms between 1972 and 1998, with follow-up of death until 31 December 2017. Analyses were performed on 114,380 respondents,

Results

The hazard of death was closely associated with gender, age, and education. The hazard ratios (HR) for death and the $95 \%$ confidence intervals $(\mathrm{Cl})$ by risk factors were similar in the four cohorts. After adjustment for demographic and environmental, modifiable factors, the HR for death was $1.90(95 \% \mathrm{Cl} 1.80-2.00)$ for breathlessness score $3,1.28$ (1.21-1.37) for cough/phlegm score 5 and 1.09 (1.05-1.14) for attack of breathlessness/wheeze score 2 compared to the referent (no symptom), respectively. The cough/phlegm score was associated with death in current smokers but not in never smokers or ex-smokers. Breathlessness score was associated with death in men and women..

Conclusions

Among persons aged 45-75 years, respiratory symptoms were significant predictors of all cause mortality. Education and smoking habits influenced only the associations between coughing and mortality. The associations were independent of study sites.

Keywords: cohort study, men and women, mortality, respiratory symptoms 


\section{Introduction}

Respiratory symptoms are one of the most frequent reasons to contact health care practitioners. They are common in all populations, and the prevalence of respiratory symptoms and their determinants have been studied extensively for more than 60 years [1-4]. Respiratory symptoms may represent different pathophysiological mechanisms and diseases. Asthma, COPD and chronic bronchitis are common causes, as well as upper and lower acute airway infections, allergic diseases, cardiovascular diseases, restrictive lung diseases and other diseases. The mortality for persons with persistent cough and phlegm has been examined since 1964 [5] and for up to 30 years [6-9] in a defined geographical area. The risk of death is higher for effort-related breathlessness and chronic mucus hypersecretion than for asthmatic symptoms [6-10]

Previous studies on the association of respiratory symptoms with mortality have adjusted for gender, age, smoking, sometimes occupational exposure, but to our knowledge rarely for educational level. Socioeconomic status (SES) is associated with the prevalence of many disease, including COPD [11, 12], and is associated with mortality [13], although the mechanisms are not clear [14]. This association may be indirect and mediated through both behavioral, environmental and genetic factors. In Norway and many other countries, education is often used as a proxy for SES. Education is also an important predictor of presence of respiratory symptoms and obstructive lung disease independent of smoking and occupational airborne exposure in our communities [15, 16].

No studies on mortality are available on ordinal ratings of breathlessness, mucus hypersecretion and asthmatic symptoms with follow up time of more than 30 years and for different geographical areas within a country.

The objective was to determine the association between respiratory symptoms in four cohorts, in pooled cohorts and in strata according to sex, age, education, and smoking status. We hypothesized that self-reported respiratory symptoms in the community are strong predictors of death; and wanted to conduct i) stratified analysis by smoking habits and ii) educational level, as 
well as assess the predictive value of respiratory symptoms over 45 years.

\section{Methods}

\section{Study populations}

The study populations were derived from four cross-sectional surveys in the city of Oslo 1972 and 1998-1999, Hordaland County in 1985, 1988-1989 (including Sauda municipality in Rogaland county) and 1998-1999 [17]. Oslo is the capital of Norway with an urban population with 477,476 persons in 1972 and 499,693 persons in 1998. Hordaland county in Western Norway is a combined rural and urban (Bergen) population with 399,702 persons in 1985, 405,063 in 1988 and 428,823 in 1998. Sauda is a rural municipality in Rogaland county with 5,416 persons in 1988 .

The target populations were born 1902-1973. The sample frames were updated lists from the Norwegian Central Population Registry. Invitees were drawn at random for the 1972, 1985 and 1998-1999 surveys. The 1988-1990 survey invited all men born 1914-1958, plus a $10 \%$ sample of the general population of city of Bergen examined in 1965-1970, leading to about $6 \%$ women in this cohort. In the analyses, those included in one cohort were excluded from the later cohorts. The sampling frames comprised 158,702 persons. In the statistical analyses presented here, we included respondents who provided information on smoking status, altogether 114,380 persons (72 \%). For details, see Table 1.

The study was approved by the Committee on Medical Research Ethics, The Norwegian Data Inspectorate and The Norwegian Directorate of Health

\section{Questionnaire}

A group of five chest physicians and one epidemiologist developed a self-administered questionnaire in 1972. The questionnaire was a modification of one approved by the British Medical Research Council`s Committee on Research into Chronic Bronchitis in 1966. The validity of the Norwegian respiratory questionnaire has been examined by lung function levels and bronchial responsiveness [18], and the lack of agreement with the original British Medical Research Council questionnaire has been examined [19]. The self-reported respiratory symptoms 
poorly predicted airflow limitation measured by spirometry, as well as bronchial hyperresponsiveness measured by metacholine provocation test.

The questionnaire included 11 questions about respiratory symptoms (Table 2), covering current cough, phlegm, wheezing, periods of cough and/or phlegm and breathlessness, which were aggregated into three symptom groups. Individuals giving affirmative answers to the breathlessness questions 13-16 were given symptom scores 1 to 4; affirmative answers to the cough and/or phlegm questions 8-12 were given symptom scores 1 to 5 , and affirmative answers to the attacks of breathlessness and wheezing questions 17-18 were given symptom scores 1 to 2.

The questionnaire included also questions on smoking history [20] and occupational exposure to air pollution. Smoking was categorized as: current smokers (at the time of the study), ex-smokers (had smoked daily but had quitted) or non-smoker (had never smoked daily). Tobacco consumption was estimated from number of cigarettes $(1$ cigarette $=1 \mathrm{~g})$. The daily tobacco consumption was grouped as $<10 \mathrm{~g}, 10-19 \mathrm{~g}$ and $\geq 20 \mathrm{~g}$. Occupational exposure to air pollution was defined by an affirmative answer to the question: "Have you been exposed to particles, gases or damp at your working place?"

\section{Follow-up}

Date of death and emigration until 31 December 2017 and education were obtained from the cause of Death Registry of the National Institute of Public Health and a linkage to a copy of the National Population Registry of the Norwegian Tax Administration. All inhabitants of Norway have a unique personal identification number that allows complete follow-up until death or emigration. In total, 156,896 people were observed, median follow-up was 26.7 years, maximum 45.2 years. The cumulative time for observation in the total sample was $3,541,219$ person-years. A total of 114,380 respondents with known smoking status were observed, median follow-up was 27.3 years, maximum 45.2 years. They represented 2,666,980 person-years at risk. 
Highest attained education was extracted from the national census for each decade and converted to number of years of education. Each person was grouped according to the maximum length of education.

\section{Statistical methods}

Descriptive statistics for the participants and symptom scores for breathlessness on effort, cough or/and phlegm and attacks of breathlessness or/and wheeze in the four cohorts are presented in frequency tables as number (\%). For start dates for observations in the cohorts, we used 5 October 1972 in the Oslo county 1972 cohort, the $15^{\text {th }}$ of the actual starting month in the Hordaland county and Sauda municipality, Rogaland county cohort 1988-1990, and the actual start date in the other two cohorts. Other missing start dates for respondents to the questionnaires were imputed using the median start date in the same cohort: 31 December 1989 in the Hordaland county and Sauda municipality, Rogaland county cohort 1988-1990 (n=100) and 5 October 1998 in the Oslo and Hordaland counties cohort 1998-1999 (n=4). Respondents with negative times to event or censoring, for example having emigrated before responding to the questionnaire or dying before an assigned median start date were excluded. The cohort members were followed until death or censored at the date of emigration or end of follow-up on 31 December 2017. For some people that emigrated $(n=231)$, we did not have an exact date of emigration, but only an interval. These cases were censored at the mid-point of the interval.

We did not impute missing values for other variables than the start date and the date of emigration. Among the respondents included, we had complete data on age, sex, smoking status, $97.5 \%$ had complete data on education, and $93.8 \%$ on occupational exposure as well.

All analyses were multivariable, adjusting for sex, age (continuous variable), education $(<10,11-$ $13, \geq 14$ years), smoking habits (never, ex-, current-smoker) and occupational exposure (dust/fume vs. none). The results are presented as hazard ratios (HR) of death with $95 \%$ confidence intervals (Cl). The four cohorts were pooled, and the association of symptom scores of breathlessness on effort, cough or/and phlegm and attacks of breathlessness or/and wheeze with all-cause mortality 
in the total pooled cohort and in subgroups was analyzed using multivariable Cox proportional hazards analysis, entering symptom scores of breathlessness on effort, cough or/and phlegm and attacks of breathlessness or/and wheeze simultaneously into the models. We used time on study as the dependent variable in the Cox models. These analyses were prepared using shared frailty for study cohort, i.e. incorporating cluster-specific random effects to account for within-cluster homogeneity in outcomes [21].

We conducted analyses for subgroups according to sex, age $(15-29,30-44,45-59, \geq 60$ years), education, and smoking status using a similar approach with shared frailty for study cohort.

The proportional hazards assumption was checked graphically using log-log plots and was considered acceptable. We chose a significance level of 0.05 using two-sided tests. Stata version 16.1 (StataCorp, College Station, Tx, USA) was used for all statistical analyses.

\section{Results}

Study participants and response rates

The response rates of those invited for the four surveys declined from $89 \%$ in the survey in Oslo 1972 to $67 \%$ in the survey of Oslo and Hordaland county in 1998. From 1972 to 1998, the proportion of respondents with higher education and those reporting occupational exposure to air pollution increased, while the proportion of smokers decreased (Table 3).

\section{Respiratory symptoms}

Of the respondents, $20 \%$ reported breathlessness on effort, $35 \%$ cough or phlegm and $25 \%$ wheeze or attacks of breathlessness (Table 4). A larger proportion of respondents reported respiratory symptoms in 1998 in Oslo and Hordaland counties compared to the 1972 and 1985 surveys, in particular symptoms related to cough and phlegm.

\section{Smoking status}


The prevalence of cough and phlegm did not differ between never smokers and ex-smokers (Table 5). However, breathless on effort, attacks of breathlessness and wheeze were more prevalent in current smokers than never smokers.

\section{Mortality}

Altogether 45,835 respondents died during follow up. The overall HR of death for respondents versus non-respondents was $0.64(95 \% \mathrm{Cl} 0.63-0.65)$ after adjustment for gender, age and education (Supplement, Table 1). The pattern of increasing HR of death in men, by higher age and lower attained education were identical for the four cohorts (data not shown).

\section{Respiratory symptoms and mortality}

\section{Cohorts}

Respiratory symptoms were associated with death in all four cohorts, although more consistent across cohorts for breathlessness on effort than for cough and phlegm (Table 6). No clear association was observed between deaths and attacks of breathlessness and wheezing. The HR of breathlessness score 4 was not statistically significant from that of breathlessness score 3 . An increased HR with higher symptom scores for cough and phlegm was only observed in two of the surveys, Oslo county cohort 1972 and Hordaland county and Sauda municipality, Rogaland county cohort 1988-1990.

\section{Pooled cohorts}

The HR of death in the pooled cohorts increased with number of positive symptoms in all three symptom groups except for breathlessness on effort score, where the HR ratio for death was similar for score 3 and 4 (Table 7). The HR was weakened only for cough and phlegm by adjustment for smoking and education. In stratified analyses, the breathlessness score was associated with death in men and women.

The risk of death by respiratory symptoms were almost identical in the strata according to highest attained education (Supplement, Table 2). The HR of death was similar across most levels of the 
cough and phlegm scores in never smokers and ex-smokers, but unambiguous among current smokers (Supplement, Table 3). The symptoms of attacks of breathlessness and wheeze were poor predictors of death.

There was an increased HR of death by higher scores of breathlessness on effort for those aged $>30$ years, but no apparent trend for those aged 15-29 years. Except for the age group 1529 years the risk of death was higher for breathlessness score 3 than score 4 , although statistically not significant (Supplement, Table 4). Cough and phlegm scores were associated with increased mortality except for the age group $<30$ years. Attacks of breathlessness and wheeze showed little association with death in the age strata, except among those aged $45-59$ years.

\section{Follow up time}

In a Kaplan-Meier plot (Fig. 1), the HR of death increased with increasing load of respiratory symptoms for breathlessness on effort and for cough and phlegm, and asthma attacks and wheeze. This trend was observed over the whole period of 45 years of follow-up.

\section{Discussion}

In long-term follow up of four general population surveys between 1972 and 1998, we have found associations of respiratory symptoms with mortality, with higher hazards of death with increasing symptom load. The pooled cohort, comprised subjects with the age span 15 to 75 years living in urban as well as rural areas. The pattern of associations was similar across the four cohorts, which supports the robustness and external validity of the findings. The association of breathlessness on effort with death was present in strata according to age, sex, level of education, and smoking status. Cough and phlegm score was similarly associated with death in strata according to sex, education, age $>29$ years and in current smokers, but not in ex-smokers and never smokers. In contrast, there was little association of attacks of breathlessness and wheeze with mortality in the stratified analyses.

The findings in the present study are largely in agreement with previous studies of respiratory 
symptoms with shorter duration of follow up [5-8, 22-26], including studies in elderly populations $[27,28]$.

The increasing HR for death with ordinal ratings of respiratory symptoms in this study is consistent with previous reports for graded dyspnoea with 43 years of follow up [29], with increasing HR with increasing number of respiratory symptoms in 30-year follow up the Oslo county cohort 1972 [6] and 12-year follow up in the 1995 Nord-Trøndelag county health study [10]. The latter study used a similar questionnaire and adjusted for age, smoking, education, lung function, body mass index, physical activity and cardiovascular disease in men and women [10]. The present study was larger, covered several geographical regions and had a longer observation time than previous Norwegian studies. We adjusted for breathlessness on effort, cough and phlegm and attacks of breathlessness or wheeze in multivariable analysis, in contrast the previous studies that assessed the impact of the symptom groups separately or in fixed combinations [8]. Our findings support the recent findings of a gradient of HR for all-cause mortality with increasing number of chronic respiratory symptoms in a cohort of more than 80,000 subjects in the general population with normal spirometry and without known airway disease [30].

Important confounders for the association for respiratory symptoms and outcome were smoking, education and occupational exposure to air pollution. We controlled for these three factors at baseline; however, smoking habit as well as occupational exposures may have changed during follow-up, and respiratory symptoms may improve over time [31]. It is thus possible that there is residual confounding by smoking.

As we did not have information on cumulative smoking habits measured in pack-years, we chose daily tobacco consumption at baseline in the analyses. After 1970, smoking has declined in all cohorts of men and women in Norway [32]. In 1973, $53 \%$ of men and $32 \%$ of women aged $16-74$ years were daily smokers, in contrast to $11 \%$ and $10 \%$ in 2017 , respectively [33]. Therefore, some of the respondents who smoked and reported symptoms might have had fewer symptoms when quitting during follow up [31]. 
The pattern of an increasing HR for deaths with increasing cough and phlegm score was of similar size in the cohorts until 1990. The lack of association between respiratory symptoms and risk of deaths in the later 1998-1999 cohort may be attributed to a larger fraction (45\%) of never smokers in this cohort than the earlier ones.

We found for breathlessness on effort no effect modification among never smokers, ex-smokers, and ever smokers. However, for cough and phlegm the risk was unambiguous in current smokers, but not present in never smokers or ex-smokers.

The questions on cough and phlegm cover both acute and chronic symptoms. It is possible that a larger fraction of acute symptoms were due to viral or allergic diseases in non-smokers, than in current smokers or ex-smokers with smoking-induced chronic symptoms. The biology of airways inflammation may thus differ in smokers and non-smokers.

The symptom group of attacks of breathlessness and wheezing showed no association with mortality in either group of smoking habits. This supports previous findings in a general population cohort with 43 years of follow up [29].

Strength of the present study were the large population-based sample, length of follow-up and completeness of data, which enabled us to analyse subgroups of gender, smoking habits, age groups, education, occupational exposure, area of living and follow-up time. All-cause mortality is a robust outcome, and the Cause of Death Registry in Norway is complete and of good quality [35]. Furthermore, the self-reported symptoms are unaffected by interviewer variability. Questionnaires on respiratory symptoms are feasible for inclusion in epidemiological studies [36] and the simplicity of a questionnaire enables the use in general practice.

The participation rate in the study was high [1], and much higher than most studies are able to achieve today. Therefore, we think the sample is reasonably representative of the general population in these areas. However, non-response was not at random and there were clearly some 
differences in characteristics between respondents and non-respondents to the survey. We are not aware of any change in the linguistic meaning of each respiratory symptom from 1972 to 1998.

Some weaknesses of the study are the lack of adjustment for lung function, body mass index and physical activity and changes over time in factors like smoking and occupational exposures to air pollution. However, respiratory symptoms predict death independent of lung function [8, 9, 36].

The lack of persistence of respiratory symptoms is well known from previous studies. The persistence of answers is greater for breathlessness on effort than for cough and wheezing [18, 31, 37, 38].

Another challenge of asking about respiratory symptoms is that differences may exist in the meaning of the questions. However, our findings have been documented for two regions and is most probably valid for Norway as all persons use identical language.

The mechanisms for the associations between respiratory symptoms is not clear and may be explained in different ways. For example, the respiratory symptoms may be indicators of inflammatory disease in pulmonary, cardiovascular and other organs, or of neoplastic diseases in the lung and other organs.

This study used time on study as the time variable in the Cox models and adjusted for age at baseline. Some authors have suggested instead using age as the time variable in cohort studies $[39,40]$; however, others recommend the approach used in the present study or that this would only marginally influence the results $[41,42]$.

Respiratory symptoms are simple and cheap to collect and represent major reasons to contact health professionals. Such symptoms are strongly associated with mortality, as shown in this 
paper. Such measures could be further refined and tested for use in the assessment and monitoring of management of respiratory diseases.

In summary, respiratory symptoms of breathlessness, cough and phlegm were associated with deaths up to 45 years after baseline recording. The findings were observed across cohorts and subgroups after adjustment for age, sex, smoking habits, educational level, and occupational exposure to air pollution. This supports the robustness of the findings. 
Funding: The study received financial support from the The Royal Norwegian Council for Scientific and Industrial Research, University of Bergen and Glaxo Smith Kline, UK. The sponsors had no role in the preparation of this manuscript.

Author contributions:

Study design: AG, KS, JB, PB, RN

Data collection: AG, PB, JB

Data analyses: KS, JB

Critical revision of the manuscript: $A G, K S, J B, R N, P B$

Conflicts of interest: None in relationship to the current manuscript. 


\section{References}

[1] A. Gulsvik, Prevalence of respiratory symptoms in the city of Oslo, Scandinavian journal of respiratory diseases 60(5) (1979) 275-85.

[2] C.M. Fletcher, P.C. Elmes, A.S. Fairbairn, C.H. Wood, The significance of respiratory symptoms and the diagnosis of chronic bronchitis in a working population, British medical journal 2(5147) (1959) 257-66.

[3] E. Huhti, Prevalence of respiratory symptoms, chronic bronchitis and pulmonary emphysema in a Finnish rural population. Field survey of age group 40-64 in the Harjavalta area, Acta tuberculosea et pneumologica Scandinavica. Supplementum (1965) Suppl 61:1-111.

[4] B. Lundback, N. Stjernberg, L. Nystrom, B. Forsberg, M. Lindstrom, K. Lundback, E. Jonsson, L. Rosenhall, Epidemiology of respiratory symptoms, lung function and important determinants. Report from the Obstructive Lung Disease in Northern Sweden Project, Tubercle and lung disease : the official journal of the International Union against Tuberculosis and Lung Disease 75(2) (1994) 116-26.

[5] T. Zeiner-Henriksen, Six year mortality related to cardiorespiratory symptoms and environmental risk factors in a sample of the Norwegian population, J Chronic. Dis 29(1) (1976) 15-33.

[6] A. Frostad, V. Soyseth, A. Andersen, A. Gulsvik, Respiratory symptoms as predictors of all-cause mortality in an urban community: a 30-year follow-up, J Intern Med 259(5) (2006) 520-9.

[7] L. Carpenter, V. Beral, D. Strachan, K.L. Ebi-Kryston, H. Inskip, Respiratory symptoms as predictors of 27 year mortality in a representative sample of British adults, BMJ 299(6695) (1989) 357-361.

[8] K. Stavem, L. Sandvik, J. Erikssen, Breathlessness, phlegm and mortality: 26 years of follow-up in healthy middle-aged Norwegian men, J Intern Med 260(4) (2006) 332-42.

[9] M.W. Knuiman, A.L. James, M.L. Divitini, G. Ryan, H.C. Bartholomew, A.W. Musk, Lung function, respiratory symptoms, and mortality: results from the Busselton Health Study, Annals of epidemiology 9(5) (1999) 297-306.

[10] L. Leivseth, T.I. Nilsen, X.M. Mai, R. Johnsen, A. Langhammer, Lung function and respiratory symptoms in association with mortality: The HUNT Study, Copd 11(1) (2014) 59-80.

[11] E. Prescott, J. Vestbo, Socioeconomic status and chronic obstructive pulmonary disease, Thorax 54(8) (1999) 737-41.

[12] A.S. Gershon, T.E. Dolmage, A. Stephenson, B. Jackson, Chronic obstructive pulmonary disease and socioeconomic status: a systematic review, Copd 9(3) (2012) 216-26.

[13] L.B. Signorello, S.S. Cohen, D.R. Williams, H.M. Munro, M.K. Hargreaves, W.J. Blot, Socioeconomic status, race, and mortality: a prospective cohort study, Am J Public Health 104(12) (2014) e98-e107.

[14] J.C. Phelan, B.G. Link, P. Tehranifar, Social conditions as fundamental causes of health inequalities: theory, evidence, and policy implications, J Health Soc Behav 51 Suppl (2010) S28-40.

[15] P.S. Bakke, R. Hanoa, A. Gulsvik, Educational level and obstructive lung disease given smoking habits and occupational airborne exposure: a Norwegian community study, Am J Epidemiol 141(11) (1995) 1080-8. [16] T.M. Eagan, A. Gulsvik, G.E. Eide, P.S. Bakke, The effect of educational level on the incidence of asthma and respiratory symptoms, Respir Med 98(8) (2004) 730-6.

[17] A. Gulsvik, S. Humerfelt, P.S. Bakke, E.R. Omenaas, S. Lehmann, Norwegian population surveys on respiratory health in adults: objectives, design, methods, quality controls and response rates, Clin Respir J 2 Suppl 1 (2008) 10-25.

[18] A. Gulsvik, P. Bakke, S. Humerfelt, E. Omenaas, V. Baste, Measurements of respiratory symptoms and 
sample size to detect a given difference between treatment groups in obstructive lung disease, Eur Respir $\operatorname{Rev}(1)$ (1991) 436-443.

[19] J.C. Brogger, P.S. Bakke, A. Gulsvik, Comparison of respiratory symptoms questionnaires, Int J Tuberc Lung Dis 4(1) (2000) 83-90.

[20] P. Bakke, A. Gulsvik, G.E. Eide, R. Hanoa, Smoking habits and lifetime occupational exposure to gases or dusts, including asbestos and quartz, in a Norwegian community, Scandinavian journal of work, environment \& health 16(3) (1990) 195-202.

[21] P.C. Austin, A Tutorial on Multilevel Survival Analysis: Methods, Models and Applications, International statistical review $=$ Revue internationale de statistique 85(2) (2017) 185-203.

[22] J. Vestbo, K.M. Knudsen, F.V. Rasmussen, The value of mucus hypersecretion as a predictor of mortality and hospitalization. An 11-year register based follow-up study of a random population sample of 876 men, Respir. Med 83(3) (1989) 207-211.

[23] A. Rosengren, L. Wilhelmsen, Respiratory symptoms and long-term risk of death from cardiovascular disease, cancer and other causes in Swedish men, Int J Epidemiol 27(6) (1998) 962-9.

[24] J. Hewitt, L. Smeeth, C.J. Bulpitt, A.J. Tulloch, A.E. Fletcher, Respiratory symptoms in older people and their association with mortality, Thorax 60(4) (2005) 331-4.

[25] P.D. Sorlie, W.B. Kannel, G. O'Connor, Mortality associated with respiratory function and symptoms in advanced age. The Framingham Study, The American review of respiratory disease 140(2) (1989) 379-84. [26] W.M. Vollmer, L.E. McCamant, L.R. Johnson, A.S. Buist, Respiratory symptoms, lung function, and mortality in a screening center cohort, Am J Epidemiol 129(6) (1989) 1157-69.

[27] T. Ahmed, J.A. Steward, M.S. O'Mahony, Dyspnoea and mortality in older people in the community: a 10-year follow-up, Age Ageing 41(4) (2012) 545-9.

[28] M. Berraho, C. Nejjari, K. El Rhazi, J.F. Tessier, J.F. Dartigues, P. Barberger-Gateau, C. Raherison, Dyspnea: a strong independent factor for long-term mortality in the elderly, The journal of nutrition, health \& aging $17(10)(2013)$ 908-12.

[29] S.M. Figarska, H.M. Boezen, J.M. Vonk, Dyspnea severity, changes in dyspnea status and mortality in the general population: the Vlagtwedde/Vlaardingen study, European journal of epidemiology 27(11) (2012) 867-76.

[30] Y. Colak, B.G. Nordestgaard, J. Vestbo, P. Lange, S. Afzal, Prognostic significance of chronic respiratory symptoms in individuals with normal spirometry, Eur Respir J 54(3) (2019).

[31] T.M. Eagan, A. Gulsvik, G.E. Eide, P.S. Bakke, Remission of respiratory symptoms by smoking and occupational exposure in a cohort study, Eur Respir J 23(4) (2004) 589-94.

[32] I. Lund, K.E. Lund, Lifetime smoking habits among Norwegian men and women born between 1890 and 1994: a cohort analysis using cross-sectional data, BMJ Open 4(10) (2014) e005539.

[33] Tobakk i Norge. Appendix table B1., 2018.

https://www.fhi.no/globalassets/dokumenterfiler/rapporter/2018/vedleggstabeller tobakk i norge.pdf.

(Accessed 3 Dec 2019 2019).

[34] M. Ekstrom, L. Schioler, R. Gronseth, A. Johannessen, C. Svanes, B. Leynaert, D. Jarvis, T. Gislason, P. Demoly, N. Probst-Hensch, I. Pin, A.G. Corsico, B. Forsberg, J. Heinrich, D. Nowak, C. Raherison-Semjen, S.C. Dharmage, G. Trucco, I. Urrutia, J. Martinez-Moratalla Rovira, J.L. Sanchez-Ramos, C. Janson, K. Toren, Absolute values of lung function explain the sex difference in breathlessness in the general population, Eur Respir J 49(5) (2017). 
[35] A.G. Pedersen, C.L. Ellingsen, Data quality in the Causes of Death Registry, Tidsskr Nor Laegeforen 135(8) (2015) 768-70.

[36] J. Vestbo, K.M. Knudsen, F.V. Rasmussen, Should we continue using questionnaires on breathlessness in epidemiologic surveys?, Am. Rev. Respir. Dis 137(5) (1988) 1114-1118.

[37] T.M. Eagan, P.S. Bakke, G.E. Eide, A. Gulsvik, Incidence of asthma and respiratory symptoms by sex, age and smoking in a community study, Eur Respir J 19(4) (2002) 599-605.

[38] J.P. Allinson, R. Hardy, G.C. Donaldson, S.O. Shaheen, D. Kuh, J.A. Wedzicha, The Presence of Chronic Mucus Hypersecretion across Adult Life in Relation to Chronic Obstructive Pulmonary Disease Development, Am J Respir Crit Care Med 193(6) (2016) 662-72.

[39] E.L. Korn, B.I. Graubard, D. Midthune, Time-to-event analysis of longitudinal follow-up of a survey: choice of the time-scale, Am. J Epidemiol 145(1) (1997) 72-80.

[40] J. Cologne, W.L. Hsu, R.D. Abbott, W. Ohishi, E.J. Grant, S. Fujiwara, H.M. Cullings, Proportional hazards regression in epidemiologic follow-up studies: an intuitive consideration of primary time scale, Epidemiology 23(4) (2012) 565-73.

[41] A.C. Thiebaut, J. Benichou, Choice of time-scale in Cox's model analysis of epidemiologic cohort data: a simulation study, Stat. Med 23(24) (2004) 3803-3820.

[42] M.J. Pencina, M.G. Larson, R.B. D'Agostino, Choice of time scale and its effect on significance of predictors in longitudinal studies, Statistics in medicine 26(6) (2007) 1343-59. 
Table 1. Flowchart of random sampled individuals in the study of respiratory symptoms and all cause deaths in Norway

\begin{tabular}{|c|c|c|c|c|c|}
\hline & $\begin{array}{l}\text { Oslo cohort } \\
1972\end{array}$ & $\begin{array}{l}\text { Hordaland } \\
\text { county cohort } \\
1985\end{array}$ & $\begin{array}{l}\text { Hordaland } \\
\text { county and } \\
\text { Sauda } \\
\text { municipality } \\
\text { Rogaland } \\
\text { county 1988- } \\
1990\end{array}$ & $\begin{array}{l}\text { Hordaland and } \\
\text { Oslo counties } \\
\text { cohort 1998- } \\
1999\end{array}$ & Total \\
\hline $\begin{array}{l}\text { Sample drawn } \\
\text { from target } \\
\text { populations (11) }\end{array}$ & 19998 & 4992 & 112235 & 25000 & 162225 \\
\hline $\begin{array}{l}\text { Persons in more } \\
\text { than one sample } \\
\text { and thus } \\
\text { excluded in later } \\
\text { samples }\end{array}$ & $1^{*}$ & 2 & 1893 & 1627 & 3523 \\
\hline $\begin{array}{l}\text { Available for } \\
\text { study }\end{array}$ & 19997 & 4990 & 110342 & 23373 & 158702 \\
\hline $\begin{array}{l}\text { Available after } \\
\text { excluding } \\
\text { missing times } \\
\text { and dates } \\
\text { ("negative } \\
\text { times") }\end{array}$ & 19892 & 4982 & 108812 & 23210 & 156896 \\
\hline $\begin{array}{l}\text { Respondents } \\
\text { (response to at } \\
\text { least } 1 \text { of } 17 \\
\text { questionnaire } \\
\text { items) }\end{array}$ & 17690 & 4461 & 77003 & 15870 & 115024 \\
\hline $\begin{array}{l}\text { Respondents to } \\
\text { smoking habits }\end{array}$ & 17680 & 4404 & 76675 & 15623 & 114380 \\
\hline $\begin{array}{l}\text { Respondents to } \\
\text { smoking habits } \\
\text { and education }\end{array}$ & 17377 & 4347 & 75406 & 14994 & 112124 \\
\hline $\begin{array}{l}\text { Respondents to } \\
\text { smoking habits, } \\
\text { education and } \\
\text { occupational } \\
\text { exposure }\end{array}$ & 16445 & 4307 & 71958 & 14765 & 107475 \\
\hline
\end{tabular}


Table 2. Questions (Q) on respiratory symptoms and scores

\begin{tabular}{|l|l|}
\hline Respiratory symptom group & Questions, score \\
\hline $\begin{array}{l}\text { Cough and phlegm (Bronchitis like } \\
\text { symptoms), scores 0-5 }\end{array}$ & $\begin{array}{l}\text { Q 8. Do you usually cough and clear your throat in the morning? } \\
\text { Yes=1, no=0. }\end{array}$ \\
\hline & Q 9. Do you usually cough during the day? Yes=1, no=0. \\
\hline & $\begin{array}{l}\text { Q 10. When you cough or clear your throat, do you usually bring up } \\
\text { phlegm? Yes=1, no=0. }\end{array}$ \\
\hline & $\begin{array}{l}\text { Q 11. Do you have cough for 3 months or more altogether during a } \\
\text { year? Yes=1, no=0. }\end{array}$ \\
\hline & $\begin{array}{l}\text { Q 12. During the last 2 years, have had a cough and/or phlegm in } \\
\text { connection with a cold for more than 3 weeks? Yes=1, no=0. }\end{array}$ \\
\hline $\begin{array}{l}\text { Attacks of breathlessness and wheeze } \\
\text { (Asthma like symptoms), scores 0-2 }\end{array}$ & Q 17. Do you have attacks of breathlessness? Yes=1, no=0. \\
\hline & Q 18. Have you ever had wheezing in your chest? Yes=1, no=0. \\
\hline Breathless, scores 0-4 & $\begin{array}{l}\text { Q 13. Are you more breathless than people of your own age when } \\
\text { walking uphill? Yes=1, no=0. }\end{array}$ \\
\hline & $\begin{array}{l}\text { Q 14. Are you breathless when you climb two flights of stairs at an } \\
\text { ordinary pace? Yes=1, no=0. }\end{array}$ \\
\hline & $\begin{array}{l}\text { Q 15. Are you breathless when you walk on level ground at an } \\
\text { ordinary pace? Yes=1, no=0 }\end{array}$ \\
\hline & Q 16. Are you breathless when at rest? Yes=1, no=0 \\
\hline &
\end{tabular}


Table 3. Number (percentages) of persons by age, sex, education, smoking habits and occupational exposure to air pollution and overal number of deaths in the four cohorts.

\begin{tabular}{|c|c|c|c|c|c|c|c|c|c|c|c|c|}
\hline & \multicolumn{2}{|c|}{$\begin{array}{l}\text { Oslo county } \\
\text { cohort } 1972 \\
\end{array}$} & \multicolumn{2}{|c|}{$\begin{array}{c}\text { Hordaland } \\
\text { county cohort } \\
1985 \\
\end{array}$} & \multicolumn{2}{|c|}{$\begin{array}{l}\text { Hordaland county } \\
\text { cohort 1988-1990* }\end{array}$} & \multicolumn{2}{|c|}{$\begin{array}{c}\text { Hordaland and } \\
\text { Oslo counties } \\
\text { cohort 1998- } \\
1999 \\
\end{array}$} & \multicolumn{2}{|l|}{ Total } & \multicolumn{2}{|c|}{ Number of deaths } \\
\hline & $\mathrm{N}$ & $\%$ & $\mathrm{~N}$ & $\%$ & $\mathrm{~N}$ & $\%$ & $\mathrm{~N}$ & $\%$ & $\mathrm{~N}$ & $\%$ & $\mathrm{~N}$ & $\%$ \\
\hline \multicolumn{13}{|l|}{ Age } \\
\hline $15-29$ yrs & 5706 & 32 & 1482 & 34 & 954 & 1 & 4641 & 30 & 12783 & 11 & 903 & 7 \\
\hline $30-44$ yrs & 3710 & 21 & 1330 & 30 & 29944 & 39 & 5433 & 35 & 40417 & 35 & 5036 & 12 \\
\hline $45-59$ yrs & 5130 & 29 & 893 & 20 & 22864 & 30 & 3730 & 24 & 32617 & 29 & 14473 & 44 \\
\hline $60-75$ yrs & 3134 & 18 & 699 & 16 & 22911 & 30 & 1819 & 12 & 28563 & 25 & 25423 & 89 \\
\hline \multicolumn{13}{|l|}{ Sex } \\
\hline Male & 8150 & 46 & 2209 & 50 & 71840 & 94 & 6944 & 44 & 89143 & 78 & 37127 & 42 \\
\hline Female & 9530 & 54 & 2195 & 50 & 4833 & 6 & 8679 & 56 & 25237 & 22 & 8708 & 35 \\
\hline \multicolumn{13}{|l|}{ Highest attained education } \\
\hline Compulsory education (<11 yrs) & 5869 & 34 & 1044 & 24 & 21015 & 28 & 1585 & 11 & 29513 & 26 & 19108 & 65 \\
\hline Medium level (11-13 yrs) & 8309 & 48 & 2342 & 54 & 40153 & 53 & 7396 & 49 & 58200 & 52 & 21651 & 37 \\
\hline University level (14+ yrs) & 3199 & 18 & 961 & 22 & 14238 & 19 & 6013 & 40 & 24411 & 22 & 4442 & 18 \\
\hline \multicolumn{13}{|l|}{ Smoking habits } \\
\hline Never smokers & 6561 & 37 & 1801 & 41 & 23250 & 30 & 7087 & 45 & 38699 & 34 & 12059 & 31 \\
\hline Ex-smokers & 2258 & 13 & 840 & 19 & 24206 & 32 & 3372 & 22 & 30676 & 27 & 13842 & 45 \\
\hline Smokers & 8861 & 50 & 1763 & 40 & 29217 & 38 & 5164 & 33 & 45005 & 39 & 19934 & 44 \\
\hline \multicolumn{13}{|l|}{ Tobacco smoked (g) per day } \\
\hline $1-9$ & 2773 & 30 & 599 & 25 & 11157 & 23 & 1992 & 26 & 16521 & 24 & 7848 & 48 \\
\hline $10-19$ & 4654 & 50 & 1254 & 53 & 24652 & 50 & 3678 & 48 & 34238 & 50 & 14055 & 41 \\
\hline $20+$ & 1868 & 20 & 525 & 22 & 13714 & 28 & 2033 & 26 & 18140 & 26 & 7719 & 43 \\
\hline \multicolumn{13}{|c|}{ Occupational exposure to air pollution } \\
\hline Yes & 3226 & 19 & 1279 & 29 & 37721 & 52 & 6150 & 40 & 48376 & 44 & 18954 & 39 \\
\hline None & 13504 & 81 & 3084 & 71 & 35411 & 48 & 9233 & 60 & 61232 & 56 & 24032 & 39 \\
\hline
\end{tabular}

*including Sauda municipality, Rogaland county 
Table 4. Number (percentage) of persons by symptom score for breathless, cough and/or phlegm and attacks of breathless and/or wheeze in four cohorts.

\begin{tabular}{|c|c|c|c|c|c|c|c|c|c|c|}
\hline & \multicolumn{2}{|c|}{$\begin{array}{c}\text { Oslo county cohort } \\
1972 \\
\end{array}$} & \multicolumn{2}{|c|}{$\begin{array}{c}\text { Hordaland } \\
\text { county cohort } \\
1985 \\
\end{array}$} & \multicolumn{2}{|c|}{$\begin{array}{c}\text { Hordaland county } \\
\text { cohort }^{*} 1988-1990 \\
\end{array}$} & \multicolumn{2}{|c|}{$\begin{array}{l}\text { Hordaland and } \\
\text { Oslo counties } \\
\text { cohort 1998-1999 }\end{array}$} & \multicolumn{2}{|l|}{ Total } \\
\hline & $\mathrm{N}$ & $\%$ & $\mathrm{~N}$ & $\%$ & $\mathrm{~N}$ & $\%$ & $\mathrm{~N}$ & $\%$ & $\mathrm{~N}$ & $\%$ \\
\hline \multicolumn{11}{|c|}{ Breathless on effort, score } \\
\hline 0 & 14358 & 81 & 3568 & 81 & 61182 & 80 & 11983 & 77 & 91091 & 80 \\
\hline 1 & 1677 & 9 & 481 & 11 & 8055 & 11 & 1868 & 12 & 12081 & 11 \\
\hline 2 & 1006 & 6 & 266 & 6 & 5148 & 7 & 1249 & 8 & 7669 & 7 \\
\hline 3 & 452 & 3 & 60 & 1 & 1746 & 2 & 395 & 3 & 2653 & 2 \\
\hline 4 & 187 & 1 & 29 & 1 & 542 & 1 & 128 & 1 & 886 & 1 \\
\hline \multicolumn{11}{|c|}{ Cough and phlegm, score } \\
\hline 0 & 10569 & 60 & 2529 & 57 & 53172 & 69 & 8004 & 51 & 74274 & 65 \\
\hline 1 & 3182 & 18 & 897 & 20 & 12862 & 17 & 3523 & 23 & 20464 & 18 \\
\hline 2 & 1746 & 10 & 409 & 9 & 4696 & 6 & 1626 & 10 & 8477 & 7 \\
\hline 3 & 972 & 5 & 290 & 7 & 2726 & 4 & 1103 & 7 & 5091 & 4 \\
\hline 4 & 666 & 4 & 163 & 4 & 1860 & 2 & 764 & 5 & 3453 & 3 \\
\hline 5 & 545 & 3 & 116 & 3 & 1357 & 2 & 603 & 4 & 2621 & 2 \\
\hline \multicolumn{11}{|c|}{ Attacks of breathlessness and wheeze, score } \\
\hline 0 & 13148 & 77 & 3183 & 75 & 55559 & 76 & 10622 & 69 & 82512 & 75 \\
\hline 1 & 2976 & 17 & 721 & 17 & 12784 & 17 & 3035 & 20 & 19516 & 18 \\
\hline 2 & 1058 & 6 & 320 & 8 & 4746 & 6 & 1633 & 11 & 7757 & 7 \\
\hline
\end{tabular}

* Including Sauda municipality, Rogaland county 
Table 5. Number (percentage) of persons by symptom score for breathless, cough and/or phlegm and attacks of breathless and/or wheeze according to smoking status.

\begin{tabular}{|c|c|c|c|c|c|c|}
\hline & \multicolumn{2}{|c|}{ Never smoker } & \multicolumn{2}{|c|}{ Ex-smoker } & \multicolumn{2}{|c|}{ Current smoker } \\
\hline & $\mathrm{N}$ & $\%$ & $\mathrm{~N}$ & $\%$ & $\mathrm{~N}$ & $\%$ \\
\hline \multicolumn{7}{|c|}{ Breathless on effort, score } \\
\hline 0 & 33320 & 86 & 24242 & 79 & 33529 & 75 \\
\hline 1 & 2829 & 7 & 2951 & 10 & 6301 & 14 \\
\hline 2 & 1809 & 5 & 2255 & 7 & 3605 & 8 \\
\hline 3 & 567 & 1 & 951 & 3 & 1135 & 3 \\
\hline 4 & 174 & 0 & 277 & 1 & 435 & 1 \\
\hline \multicolumn{7}{|c|}{ Cough and phlegm, score } \\
\hline 0 & 28993 & 75 & 22686 & 74 & 22595 & 50 \\
\hline 1 & 6039 & 16 & 4878 & 16 & 9547 & 21 \\
\hline 2 & 1758 & 5 & 1468 & 5 & 5251 & 12 \\
\hline 3 & 984 & 3 & 771 & 3 & 3336 & 7 \\
\hline 4 & 554 & 1 & 485 & 2 & 2414 & 5 \\
\hline 5 & 371 & 1 & 388 & 1 & 1862 & 4 \\
\hline \multicolumn{7}{|c|}{ Attacks of breathlessness and wheeze, score } \\
\hline 0 & 31812 & 86 & 23106 & 79 & 27594 & 64 \\
\hline 1 & 3741 & 10 & 4388 & 15 & 11387 & 26 \\
\hline 2 & 1565 & 4 & 1930 & 7 & 4262 & 10 \\
\hline
\end{tabular}


Table 6. Hazard ratios (HR) of death ${ }^{1}$ with $95 \%$ confidence intervals $(\mathrm{Cl})$ and $p$-values by respiratory symptoms separately in the four cohorts, multivariable proportional hazards regression analysis.

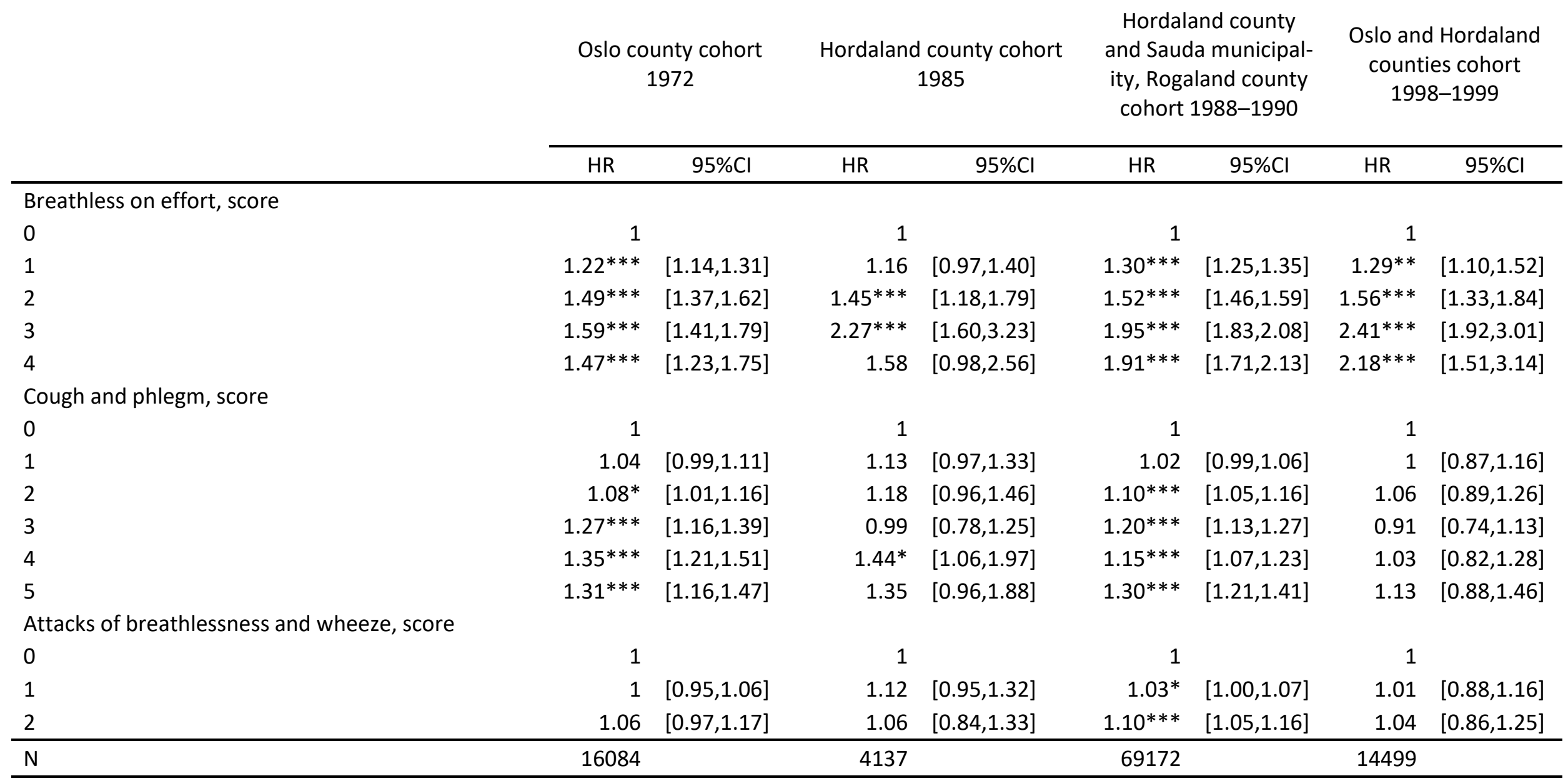

${ }^{1}$ Adjusted for age, sex, education, smoking habits and occupational exposure, in addition to the various respiratory symptoms;

$* p<0.05, * * p<0.01, * * * p<0.001$ 
Table 7. Hazard ratios (HR) of death with $95 \%$ confidence intervals $(\mathrm{Cl})$ and p-values by respiratory symptoms in the pooled cohorts, multivariable proportional hazards regression analysis.

\begin{tabular}{|c|c|c|c|c|c|c|c|c|}
\hline & \multicolumn{2}{|c|}{ All, adj. for age $/$ sex $^{1}$} & \multicolumn{2}{|c|}{ All ${ }^{2}$} & \multicolumn{2}{|c|}{ Men $^{3}$} & \multicolumn{2}{|c|}{ Women ${ }^{3}$} \\
\hline & $H R$ & $95 \% \mathrm{Cl}$ & $\mathrm{HR}$ & $95 \% \mathrm{Cl}$ & HR & $95 \% \mathrm{Cl}$ & $\mathrm{HR}$ & $95 \% \mathrm{Cl}$ \\
\hline \multicolumn{9}{|c|}{ Breathless on effort, score } \\
\hline 0 & \multicolumn{2}{|c|}{1} & \multicolumn{2}{|c|}{1} & \multicolumn{2}{|c|}{1} & \multicolumn{2}{|c|}{1} \\
\hline 2 & $1.51 * * *$ & {$[1.46,1.56]$} & $1.52 * * *$ & {$[1.47,1.57]$} & $1.55^{* * *}$ & {$[1.49,1.62]$} & $1.36 * * *$ & {$[1.26,1.48]$} \\
\hline 3 & $1.85^{* * *}$ & {$[1.75,1.94]$} & $1.90 * * *$ & {$[1.80,2.00]$} & $2.00^{* * *}$ & {$[1.89,2.12]$} & $1.52 * * *$ & {$[1.35,1.72]$} \\
\hline 4 & $1.75^{* * *}$ & {$[1.60,1.90]$} & $1.78^{* * *}$ & {$[1.63,1.95]$} & $1.92^{* * *}$ & {$[1.74,2.13]$} & $1.39 * * *$ & {$[1.16,1.68]$} \\
\hline \multicolumn{9}{|c|}{ Cough and phlegm, score } \\
\hline 0 & \multicolumn{2}{|c|}{1} & \multicolumn{2}{|c|}{1} & \multicolumn{2}{|c|}{1} & \multicolumn{2}{|c|}{1} \\
\hline 1 & $1.09 * * *$ & {$[1.07,1.12]$} & $1.03 *$ & {$[1.00,1.06]$} & $1.04 *$ & {$[1.01,1.07]$} & 1.02 & {$[0.96,1.09]$} \\
\hline 2 & $1.26 * * *$ & {$[1.22,1.31]$} & $1.10^{* * *}$ & {$[1.06,1.14]$} & $1.10^{* * *}$ & {$[1.05,1.14]$} & $1.13^{* *}$ & {$[1.03,1.23]$} \\
\hline 3 & $1.38 * * *$ & {$[1.32,1.44]$} & $1.19 * * *$ & {$[1.14,1.25]$} & $1.22^{* * *}$ & {$[1.16,1.29]$} & 1.09 & {$[0.98,1.21]$} \\
\hline 4 & $1.44^{* * *}$ & {$[1.37,1.52]$} & $1.20 * * *$ & {$[1.13,1.27]$} & $1.18^{* * *}$ & {$[1.11,1.26]$} & $1.28^{* * *}$ & {$[1.12,1.46]$} \\
\hline 5 & $1.55^{* * *}$ & {$[1.47,1.65]$} & $1.28 * * *$ & {$[1.21,1.37]$} & $1.30^{* * *}$ & {$[1.22,1.39]$} & $1.20 *$ & {$[1.03,1.39]$} \\
\hline $\mathrm{N}$ & \multicolumn{2}{|c|}{109785} & \multicolumn{2}{|c|}{103881} & \multicolumn{2}{|c|}{81510} & \multicolumn{2}{|c|}{22371} \\
\hline
\end{tabular}

${ }^{1}$ Adjusted for age, sex, study cohort and the various respiratory symptoms

${ }^{2}$ Adjusted for age, sex, education , smoking habits, occupational exposure and study cohort, in addition to the various respiratory symptoms

${ }^{3}$ Adjusted for age, education , smoking habits, occupational exposure and study cohort, in addition to the various respiratory symptoms

$* p<0.05, * * p<0.01, * * * p<0.001$ 
Figure legends.

Fig.1. Survival over 45 years according to respiratory symptoms, defined as no. of affirmative responses to items on (a) Breathlessness on effort, (b) Cough and phlegm, (c) Attacks of breathlessness and wheeze. 
(a)

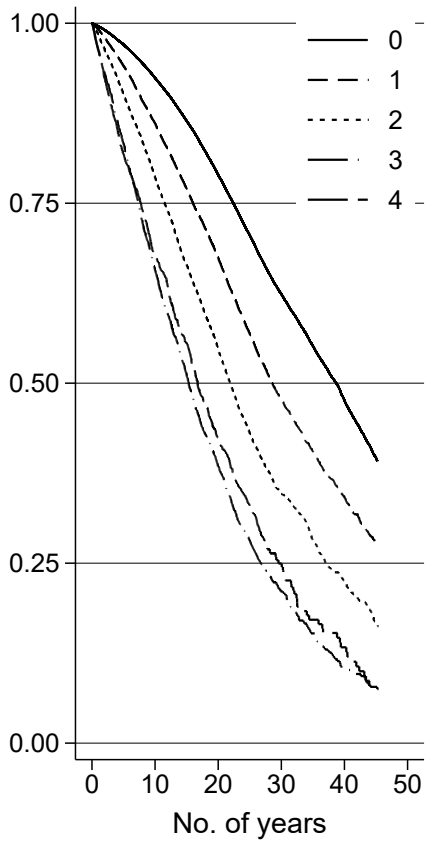

(b)

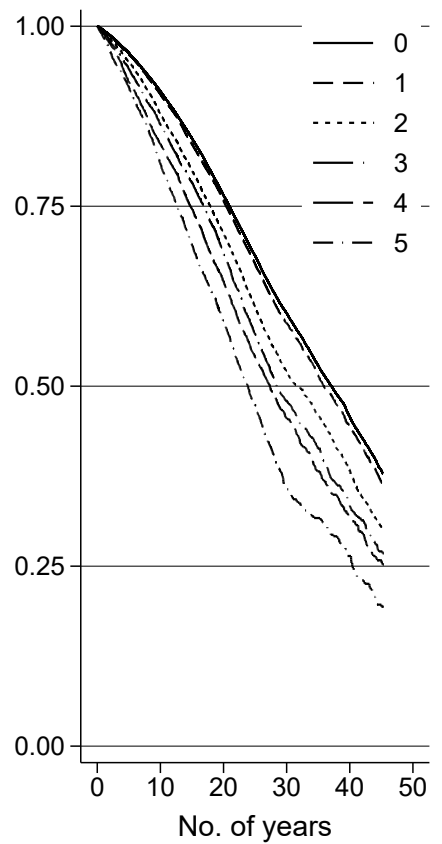

(c)
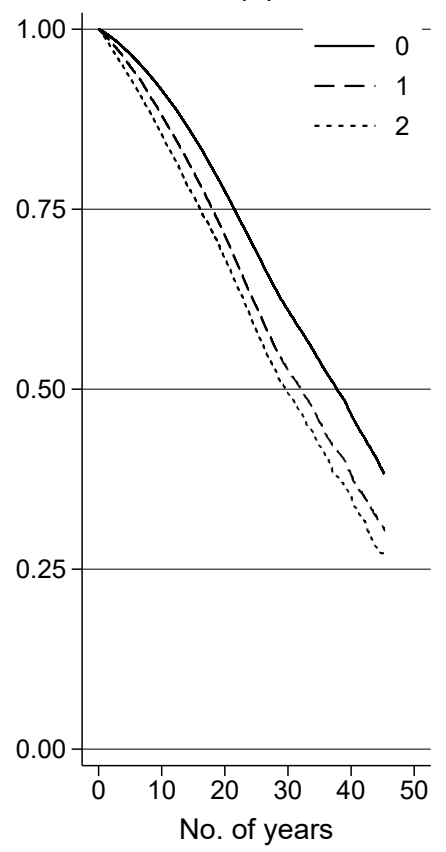


\section{Supplement}

Suppl. Table 1. Hazard ratios with $95 \%$ confidence intervals and p-values in the pooled cohort according to response in survey, multivariable proportional hazards regression analysis with shared frailty for study cohort.

\begin{tabular}{|c|c|c|}
\hline & \multicolumn{2}{|c|}{ Pooled cohort } \\
\hline & $H R$ & $95 \% \mathrm{Cl}$ \\
\hline \multicolumn{3}{|l|}{ Response status } \\
\hline Non-respondents & & {$[1.00,1.00]$} \\
\hline Respondents & $0.64 * * *$ & {$[0.63,0.65]$} \\
\hline \multicolumn{3}{|l|}{ Gender } \\
\hline Male & 1 & {$[1.00,1.00]$} \\
\hline Female & $0.59 * * *$ & {$[0.58,0.61]$} \\
\hline Age, per year & $1.11 * * *$ & {$[1.11,1.11]$} \\
\hline \multicolumn{3}{|l|}{ Highest attained education } \\
\hline Compulsory education (<11 yrs) & 1 & {$[1.00,1.00]$} \\
\hline Medium level (11-13 yrs) & $0.84 * * *$ & {$[0.82,0.85]$} \\
\hline University level (14+ yrs) & $0.51 * * *$ & {$[0.50,0.53]$} \\
\hline $\mathrm{N}$ & 151174 & \\
\hline
\end{tabular}

${ }^{*} p<0.05,{ }^{* *} p<0.01,{ }^{* * *} p<0.001$ 
Suppl. Table 2. Hazard ratios with $95 \%$ confidence intervals and p-values in pooled cohorts, stratified according to length of education. Multivariable proportional hazards regression analysis ${ }^{1}$.

\begin{tabular}{|c|c|c|c|c|c|c|}
\hline & \multirow{2}{*}{\multicolumn{2}{|c|}{$<11$ years }} & \multirow{2}{*}{\multicolumn{2}{|c|}{$11-13$ years }} & & \\
\hline & & & & & \multicolumn{2}{|c|}{$>13$ years } \\
\hline & $\mathrm{HR}$ & $95 \% \mathrm{Cl}$ & $\mathrm{HR}$ & $95 \% \mathrm{Cl}$ & $\mathrm{HR}$ & $95 \% \mathrm{Cl}$ \\
\hline \multicolumn{7}{|c|}{ Breathless on effort, score } \\
\hline 0 & \multicolumn{2}{|l|}{1} & \multicolumn{2}{|l|}{1} & \multicolumn{2}{|l|}{1} \\
\hline 1 & $1.25^{* * *}$ & {$[1.19,1.31]$} & $1.32 * * *$ & {$[1.26,1.38]$} & $1.23 * * *$ & {$[1.10,1.37]$} \\
\hline 2 & $1.51 * * *$ & {$[1.44,1.59]$} & $1.52 * * *$ & {$[1.44,1.60]$} & $1.57^{* * *}$ & {$[1.37,1.80]$} \\
\hline 3 & $1.86 * * *$ & {$[1.73,2.00]$} & $1.96 * * *$ & {$[1.81,2.12]$} & $1.89 * * *$ & {$[1.45,2.45]$} \\
\hline 4 & $1.78 * * *$ & {$[1.58,2.00]$} & $1.82 * * *$ & {$[1.57,2.09]$} & $1.75^{*}$ & {$[1.03,2.99]$} \\
\hline \multicolumn{7}{|c|}{ Cough and phlegm, score } \\
\hline 0 & \multicolumn{2}{|l|}{1} & \multicolumn{2}{|l|}{1} & \multicolumn{2}{|l|}{1} \\
\hline 1 & 1.02 & {$[0.98,1.06]$} & $1.05^{*}$ & {$[1.01,1.09]$} & 0.99 & {$[0.91,1.08]$} \\
\hline 2 & $1.15^{* * *}$ & {$[1.08,1.22]$} & $1.06^{*}$ & {$[1.01,1.12]$} & 1.09 & {$[0.96,1.23]$} \\
\hline 3 & $1.18^{* * *}$ & {$[1.10,1.26]$} & $1.19 * * *$ & {$[1.12,1.28]$} & $1.27^{* *}$ & {$[1.07,1.51]$} \\
\hline 4 & $1.14^{* *}$ & {$[1.05,1.24]$} & $1.24 * * *$ & {$[1.14,1.34]$} & $1.42 * * *$ & {$[1.16,1.73]$} \\
\hline 5 & $1.22 * * *$ & {$[1.11,1.34]$} & $1.34 * * *$ & {$[1.23,1.47]$} & $1.28 *$ & {$[1.01,1.61]$} \\
\hline \multicolumn{7}{|c|}{ Attacks of breathlessness and wheeze, score } \\
\hline 0 & \multicolumn{2}{|l|}{1} & \multicolumn{2}{|l|}{1} & \multicolumn{2}{|l|}{1} \\
\hline 1 & 1.01 & {$[0.97,1.05]$} & 1.03 & {$[0.99,1.07]$} & $1.12^{*}$ & {$[1.03,1.23]$} \\
\hline 2 & 1.06 & {$[1.00,1.13]$} & $1.09 * *$ & {$[1.03,1.16]$} & $1.26^{* *}$ & {$[1.09,1.46]$} \\
\hline $\mathrm{N}$ & \multicolumn{2}{|l|}{25950} & \multicolumn{2}{|l|}{54390} & \multicolumn{2}{|l|}{23541} \\
\hline
\end{tabular}

${ }^{*} p<0.05, * * p<0.01, * * * p<0.001$

${ }^{1}$ Adjusted for age, sex, smoking history, occupational exposure and study cohort, in addition to the various respiratory symptoms 
Suppl. Table 3. Hazard ratios with $95 \%$ confidence intervals and $p$-values in pooled cohorts, stratified according to smoking status. Multivariable proportional hazards regression analysis.

\begin{tabular}{|c|c|c|c|c|c|c|}
\hline & \multirow{2}{*}{\multicolumn{2}{|c|}{ Never-smokers $^{1}$}} & \multirow{2}{*}{\multicolumn{2}{|c|}{ Ex-smokers ${ }^{2}$}} & & \\
\hline & & & & & \multicolumn{2}{|c|}{ Current-smokers ${ }^{2}$} \\
\hline & $\mathrm{HR}$ & $95 \% \mathrm{Cl}$ & $\mathrm{HR}$ & $95 \% \mathrm{Cl}$ & $\mathrm{HR}$ & $95 \% \mathrm{Cl}$ \\
\hline \multicolumn{7}{|c|}{ Breathless on effort, score } \\
\hline 0 & \multicolumn{2}{|l|}{1} & \multicolumn{2}{|l|}{1} & \multicolumn{2}{|l|}{1} \\
\hline 1 & $1.26 * * *$ & {$[1.17,1.35]$} & $1.26 * * *$ & {$[1.19,1.34]$} & $1.27^{* * *}$ & {$[1.22,1.33]$} \\
\hline 2 & $1.50 * * *$ & {$[1.39,1.62]$} & $1.52 * * *$ & {$[1.42,1.62]$} & $1.46^{* * *}$ & {$[1.38,1.54]$} \\
\hline 3 & $1.80 * * *$ & {$[1.59,2.05]$} & $1.92 * * *$ & {$[1.75,2.11]$} & $1.89 * * *$ & {$[1.74,2.06]$} \\
\hline 4 & $1.42 * *$ & {$[1.14,1.78]$} & $2.24 * * *$ & {$[1.90,2.64]$} & $1.63 * * *$ & {$[1.43,1.87]$} \\
\hline \multicolumn{7}{|c|}{ Cough and phlegm, score } \\
\hline 0 & \multicolumn{2}{|l|}{1} & \multicolumn{2}{|l|}{1} & \multicolumn{2}{|l|}{1} \\
\hline 1 & $0.93 * *$ & {$[0.87,0.98]$} & 1.05 & {$[1.00,1.11]$} & $1.05^{*}$ & {$[1.01,1.10]$} \\
\hline 2 & 1.07 & {$[0.97,1.18]$} & 0.99 & {$[0.91,1.09]$} & $1.12^{* * *}$ & {$[1.07,1.18]$} \\
\hline 3 & 0.93 & {$[0.82,1.05]$} & 1.05 & {$[0.93,1.18]$} & $1.27^{* * *}$ & {$[1.19,1.35]$} \\
\hline 4 & 0.93 & {$[0.78,1.11]$} & 1.15 & {$[1.00,1.32]$} & $1.23^{* * *}$ & {$[1.14,1.31]$} \\
\hline 5 & 1.04 & {$[0.86,1.27]$} & $1.43^{* * *}$ & {$[1.23,1.67]$} & $1.27^{* * *}$ & {$[1.18,1.37]$} \\
\hline \multicolumn{7}{|c|}{ Attacks of breathlessness and wheeze, score } \\
\hline 0 & \multicolumn{2}{|l|}{1} & \multicolumn{2}{|l|}{1} & \multicolumn{2}{|l|}{1} \\
\hline 1 & 1.02 & {$[0.95,1.09]$} & 1.02 & {$[0.96,1.07]$} & 1 & {$[0.96,1.04]$} \\
\hline 2 & 1.11 & {$[0.99,1.23]$} & 1.06 & {$[0.98,1.16]$} & 1.05 & {$[0.99,1.11]$} \\
\hline $\mathrm{N}$ & \multicolumn{2}{|l|}{34916} & \multicolumn{2}{|l|}{24969} & \multicolumn{2}{|l|}{38253} \\
\hline
\end{tabular}

${ }^{*} \mathrm{p}<0.05,{ }^{* *} \mathrm{p}<0.01,{ }^{* * *} \mathrm{p}<0.001$

${ }^{1}$ Adjusted for age, sex, education, occupational exposure and study cohort, in addition to the various respiratory symptoms

${ }^{2}$ Adjusted for age, sex, education, daily smoking volume, occupational exposure and study cohort, in addition to the various respiratory symptoms 
Suppl. Table 4. Hazard ratios with $95 \%$ confidence intervals and p-values in pooled cohorts, stratified according to age. Multivariable proportional hazards regression analysis ${ }^{1}$.

\begin{tabular}{|c|c|c|c|c|c|c|c|c|}
\hline & \multicolumn{2}{|c|}{$15-29$ years } & \multicolumn{2}{|c|}{$30-44$ years } & \multicolumn{2}{|c|}{$45-59$ years } & \multicolumn{2}{|c|}{$60-75$ years } \\
\hline & $\mathrm{HR}$ & $95 \% \mathrm{Cl}$ & $\mathrm{HR}$ & $95 \% \mathrm{Cl}$ & $\mathrm{HR}$ & $95 \% \mathrm{Cl}$ & $\mathrm{HR}$ & $95 \% \mathrm{Cl}$ \\
\hline \multicolumn{9}{|c|}{ Breathless on effort, score } \\
\hline 0 & 1 & {$[1.00,1.00]$} & 1 & {$[1.00,1.00]$} & 1 & {$[1.00,1.00]$} & 1 & {$[1.00,1.00]$} \\
\hline 1 & 1.14 & {$[0.91,1.43]$} & $1.23 * * *$ & {$[1.12,1.35]$} & $1.33^{* * *}$ & {$[1.26,1.40]$} & $1.31 * * *$ & {$[1.25,1.36]$} \\
\hline 2 & $2.01 * * *$ & {$[1.51,2.67]$} & $1.43^{* * *}$ & {$[1.26,1.62]$} & $1.61 * * *$ & {$[1.50,1.72]$} & $1.59 * * *$ & {$[1.52,1.67]$} \\
\hline 3 & 0.58 & {$[0.19,1.83]$} & $1.85^{* * *}$ & {$[1.45,2.35]$} & $1.99 * * *$ & {$[1.80,2.21]$} & $2.10 * * *$ & {$[1.97,2.24]$} \\
\hline 4 & $3.77 * *$ & {$[1.51,9.40]$} & 0.97 & {$[0.67,1.42]$} & $1.80 * * *$ & {$[1.53,2.12]$} & $1.95 * * *$ & {$[1.74,2.19]$} \\
\hline \multicolumn{9}{|c|}{ Cough and phlegm, score } \\
\hline 0 & 1 & {$[1.00,1.00]$} & 1 & {$[1.00,1.00]$} & 1 & {$[1.00,1.00]$} & 1 & {$[1.00,1.00]$} \\
\hline 1 & 1.05 & {$[0.87,1.27]$} & $1.11^{*}$ & {$[1.02,1.20]$} & 1.01 & {$[0.96,1.06]$} & 1.02 & {$[0.99,1.06]$} \\
\hline 2 & $1.33^{*}$ & {$[1.06,1.66]$} & $1.23 * * *$ & {$[1.11,1.37]$} & $1.10^{* *}$ & {$[1.03,1.18]$} & $1.09 * *$ & {$[1.03,1.15]$} \\
\hline 3 & 1.05 & {$[0.77,1.42]$} & $1.37 * * *$ & {$[1.20,1.56]$} & $1.22 * * *$ & {$[1.13,1.32]$} & $1.12^{* *}$ & {$[1.04,1.19]$} \\
\hline 4 & 1.36 & {$[0.98,1.89]$} & $1.47 * * *$ & {$[1.26,1.71]$} & $1.23^{* * *}$ & {$[1.12,1.35]$} & $1.10^{*}$ & {$[1.02,1.19]$} \\
\hline 5 & 1.11 & {$[0.72,1.71]$} & $1.76 * * *$ & {$[1.49,2.09]$} & $1.36 * * *$ & {$[1.23,1.51]$} & $1.15^{* *}$ & {$[1.06,1.26]$} \\
\hline \multicolumn{9}{|c|}{ Attacks of breathlessness and wheeze, score } \\
\hline 0 & 1 & {$[1.00,1.00]$} & 1 & {$[1.00,1.00]$} & 1 & {$[1.00,1.00]$} & 1 & {$[1.00,1.00]$} \\
\hline 1 & 1.02 & {$[0.85,1.24]$} & 1.03 & {$[0.95,1.11]$} & $1.06^{*}$ & {$[1.01,1.11]$} & 0.99 & {$[0.95,1.03]$} \\
\hline 2 & 1.04 & {$[0.78,1.39]$} & 1.04 & {$[0.93,1.17]$} & $1.07^{*}$ & {$[1.00,1.15]$} & 1.02 & {$[0.97,1.09]$} \\
\hline $\mathrm{N}$ & 11832 & & 37817 & & 29613 & & 24619 & \\
\hline
\end{tabular}

${ }^{1}$ Adjusted for sex, education, smoking habits, occupational exposure and cohort, in addition to the various respiratory symptoms 